\title{
Connection of Old and New Mathematics on Works of Islamic Mathematician with a Look to Role of History of Mathematics on Education of Mathematics
}

\author{
Saeed Seyed Agha Banihashemi \\ I.H.University, Tehran, Iran
}

Saghbani@ih u.ac.ir

\begin{abstract}
In this article we are going to discuss how new and old mathematics are related on works of Islamic mathematician and how history of mathematics can help education of mathematics to improve and motivate it.
\end{abstract}

Keywords: history of mathematics, education of mathematics, invention, Greek mathematics, Islamic mathematics, Indian mathematics

\section{Introduction}

In history of mathematics we must study history of mathematics of all civilization because without study in this way we may do mistake .on basis of my project in Iran we collected about 6000 of mathematical manuscript of different libraries of about 1600 author. With these manuscript we came to know that fifth century of hijry was maximum activity of Islamic mathematician in the Islamic empire(indaex1) \% 30 of these are number theory and $\% 30$ is geometry and \%30 is algebra and ten percent is application of mathematics. Intelligent people faced a religion, which in this religion science are most important phenomena

"If today and tomorrow of Muslim are same they are not Muslim "

That means every day Muslim must learn new things .So they studied Greek and Indian manuscript so a dry land was watered by Greek and Indian mathematics. In this condition Benmusa and their brothers employed Harni to translate these manuscripts. So in other way they did history of mathematics the best one was Phage nasradin Tusi which in their manuscript we can see he state weakness and power point of Greek and Indian manuscript.

\section{Role of History of Mathematics on Education of Mathematics}

One of the basic fact of history of mathematics it teaches to student that science is works of all civilization what ever we have are task of all civilization so nice feel comes to them that all people have cooperate in what we have now .Students with help of history of mathematics learn that big mathematician has done mistake so if they have done mistake can try again look to mistake of ferma on

Material published as part of these proceedings, either on-line or in print, is copyrighted by Informing Science. Permission to make digital or paper copy of part or all of these works for personal or classroom use is granted without fee provided that the copies are not made or distributed for profit or commercial advantage AND that copies 1) bear this notice in full and 2) give the full citation on the first page. It is permissible to abstract these works so long as credit is given. To copy in all other cases or to republish or to post on a server or to redistribute to lists requires specific permission from the publisher at Publisher@InformingScience.org claim that $F_{n}=2^{2^{n}}+1, \mathrm{n}=1,2,3, \ldots \ldots \ldots$

Is a prime number uler proved that 641 are a factor of $F_{5}$.

Most important of education of mathematics aim is make a quite and interesting class we have very nice and interesting story in Greek, Indian, and 


\section{Connection of Old and New Mathematics}

Islamic mathematics which can help teachers to control the classes

\section{Some Examples}

\section{Example 1}

Abolvafa Bozjani, one of the famous mathematicians of 328 of Hejry (940 .A.D), had very nice books which all translated in English and French. In his book with the name geometry operation there is very beautiful problem can make student interest and better thinking as follow:

"How we can make with three equal squares a new square?"

Let the student think for few minutes and compare their work with Bozjani method.

Solution: Let a,b,c three equal square we divide two of them into two parts by diameter as shown in Figure 1.

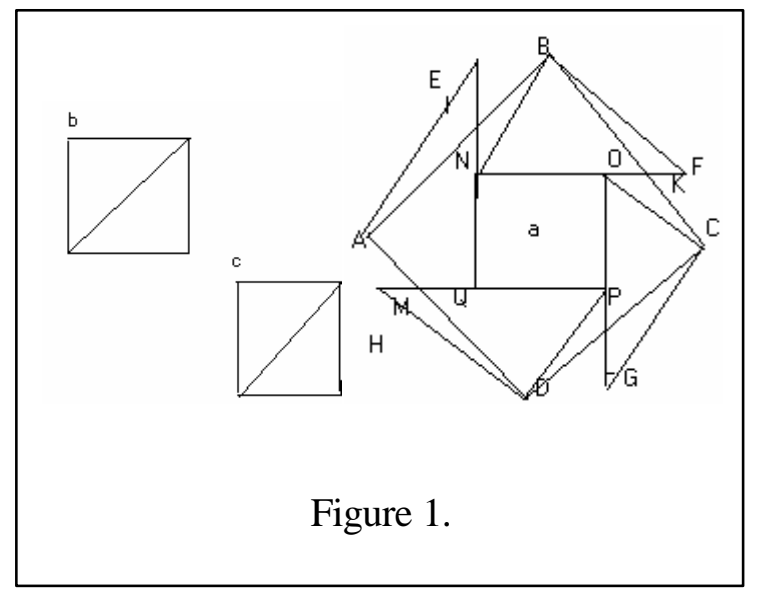

\section{Example -2}

Division of a line into equal parts. If we want to divide $\mathrm{AB}$ into three parts we continue from $\mathrm{A}$ and $\mathrm{B}$ in different direction we call $B B^{\prime}=a, A A^{\prime}=2 a$ so $\mathrm{BM}=(1 / 3) \mathrm{AB}$. (See Figure 2.)

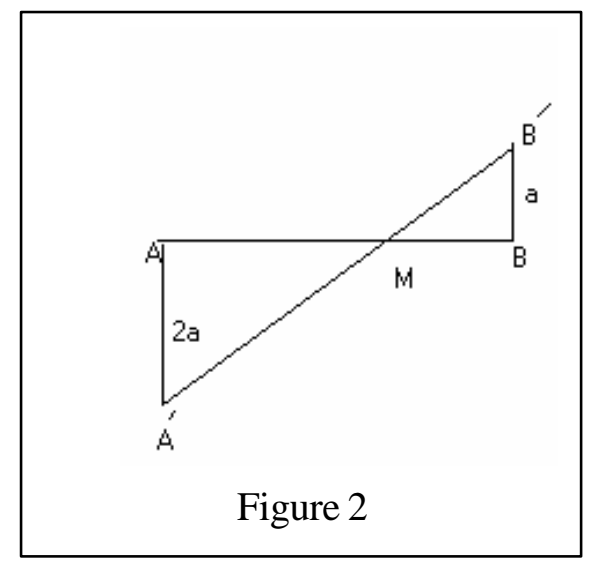

\section{Trisection of Triangle}

Another important aim of education of mathematics is to learn better thinking history of mathematics have this tools. I think best problems for student for thinking is problems of all civilizations like trisection of angle, squaring circle,

In this section we see two method of trisection of angle from different civilization.

\section{1-2-3-Hippas Method}

When the given angle BAF is trisected as follows (Figure 3):

1- Construct a square $\mathrm{ABCD}$ on $\mathrm{AB}$ such that ray $\mathrm{AF}$ lies in the interior of $\angle \mathrm{BAD}$.

2- Draw the quadratix DE and let $\mathrm{X}$ be its point of intersection with AF.

3- Draw XC parallel to BA.

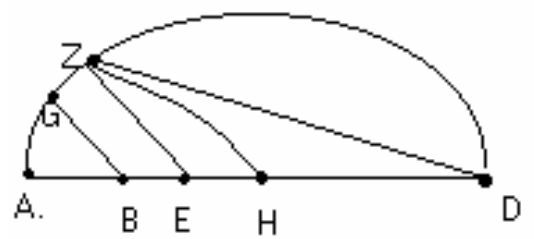

Figure 3 
4- Construct the point $\mathrm{H}$ on Ad such that $A H=\frac{1}{3} A G$.

5- Draw HY parallel to AB

6- Draw AY .

Then $\angle \mathrm{ABY}$ is the required angle.

\section{1-2-4- abosahl Kohi method}

$\mathrm{He}$ is one of the most important mathematicians of fourth century (hejry) from south of Caspian Sea. He was magician he was interesting on central of gravity because of his job then he became interest to mathematics.

He started with following dilemma:

Suppose we have semi circle AZD with diameter AD an center $\mathrm{H}$ with angle $\mathrm{ABG}$ (Figure 4). We want to find $\mathrm{E}$ such that $\mathrm{EZ}$ parallel with $\mathrm{BG}$ then $E Z^{2}=E H \cdot E D$

Now we consider method of Kohi for trisection of angle (Figure 4).

Continue $\mathrm{AB}$ up to $\mathrm{D}$ which length of $\mathrm{BD}$ is optional. Draw a semi circle with diameter $\mathrm{AD}$ which $\mathrm{H}$ is middle of $\mathrm{AD}$. $\mathrm{EZ}$ is parallel such that $E H \cdot E D=E Z^{2}$ then draw EZ, ZD, BT parallel to $\mathrm{ZH}$ in this case $\angle \mathrm{ABT}=2<\mathrm{TBG}$. So $<\mathrm{ABG}=<\mathrm{ABT}+<\mathrm{TBG}=2<\mathrm{TBG}+<\mathrm{TBG}=3<\mathrm{TBG}$.

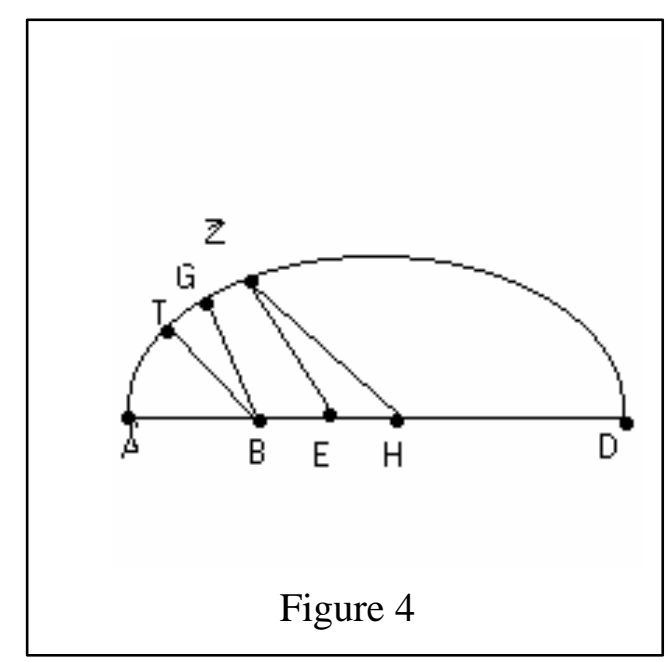

He prove above statement as follows:

We have $E H \cdot E D=E Z^{2} \Rightarrow \frac{E D}{E Z}=\frac{E Z}{E H}$ Since two triangle HEZ, ZED are common on E so these two are analogous, therefore $\angle \mathrm{EZH}=<\mathrm{D}$ but two arm $\mathrm{ZH}$, HD of triangle $\mathrm{ZHD}$ are equal though $\angle \mathrm{HZD}=\angle \mathrm{D}$, $<\mathrm{EZH}=<\mathrm{HZD}$ but $<\mathrm{EHZ}$ is external angle of triangle $\mathrm{ZHD}$. So

$<\mathrm{EHZ}=<\mathrm{HZD}+<\mathrm{D}=2<\mathrm{HZD}$ but $<\mathrm{BEZ}$ is external of triangle $\mathrm{ZEH}$ we have $<\mathrm{BEZ}=<\mathrm{EZH}+<\mathrm{EHZ}=<\mathrm{HZD}+2<\mathrm{HZD}=<\mathrm{HZD}$ therefore $<\mathrm{EHZ}=(2 / 3)<\mathrm{ABG}$ because $\mathrm{BT}$ is parallel $\mathrm{ZH}$ we have $<\mathrm{ABT}=(2 / 3)<\mathrm{ABG}$ in other way $<\mathrm{TBG}=(1 / 3)<\mathrm{ABG}$.

\section{Squaring the Circle by the Ramrajan Method:}

Squaring the circle is another problem which different civilization was interested (Figure 5).

It is seems very simple according to idea of students but when they start to calculate they will see it is not possible because

$$
\text { Area of a circle with diameter } 1 \text { is equal to } \begin{aligned}
& A=\pi R^{2} \text { ifR }=1 \Rightarrow A=\pi \\
& A=x^{2} \Rightarrow \pi=x^{2} \Rightarrow x=\sqrt{\pi}
\end{aligned}
$$

Since $\pi$ is unknown never we can find $\mathrm{x}$. But different mathematician from different civilization tried to find a system to do drawing one these mathematicians are Ramrujan from India though he had very short life but it was full so success. 


\section{Connection of Old and New Mathematics}

Let PQR be a circle with center O of which a diameters PR. Bisect $\mathrm{PO}$ at $\mathrm{H}$ and let $\mathrm{T}$ be the point of trisection of OR near R. Draw TQ perpendicular PR and place the chord RS=TQ. Join PS and draw $\mathrm{OM}$ and TN parallel to RS .Place a chord $\mathrm{PK}=\mathrm{PM}$ and draw the tangent $\mathrm{PL}=\mathrm{MN}$.Join RL, RK and KL. Cut off RC=RH .Draw CD parallel to KL meeting RL at D (Figure 6).

Then the square on RD will be equal to the circle PQR (in area) approximately. For $R S^{2}=\frac{5}{36} d^{2}$

Where $\mathrm{d}$ is diameter of the circle.

Therefore $P S^{2}=\frac{31}{36} d^{2}$. But PL and PK are equal to MN and PM respectively. Therefore $P K^{2}=\frac{31}{144} d^{2}, P L^{2}=\frac{31}{324} d^{2}$ and hence $R K^{2}=P R^{2}-P K^{2}=\frac{113}{144} d^{2}$ and $R L^{2}=P R^{2}+P L^{2}=\frac{355}{324} d^{2}$. But $\frac{R K}{P L}=\frac{R C}{R D}=\frac{3}{2}\left(\frac{113}{325}\right)^{1 / 2}$ and $R C=\frac{3}{4} d$.

Therefore $R D=\frac{d}{2}\left(\frac{355}{113}\right)^{1 / 2}=r \sqrt{\pi}$.
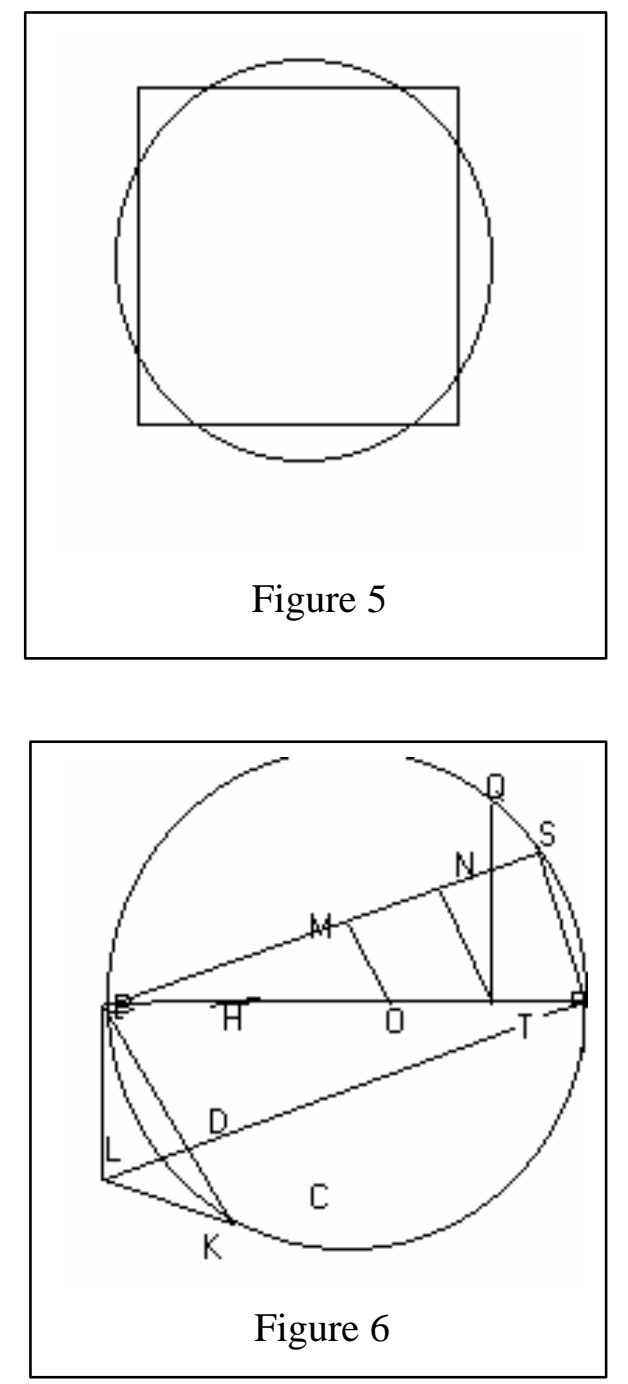

\section{Another Effect}

Another effect of the history of mathematics on education of mathematics especially for teacher is that they can understood the right root of formula in following we look to a list formula which named rungly

\section{Correct}

Ghyathedin Kashany (8 Hejry)

$\sqrt[n]{T^{n}+r} \approx T+\frac{r}{(T+r)^{n}+T^{n}}$ rung

Febunaji

$$
\begin{aligned}
& \sqrt{a^{2}+r} \approx a+\frac{r}{2} \\
& \sqrt[3]{a^{3}+r} \approx a+\frac{r}{(a+1)^{3}+a^{3}}
\end{aligned}
$$


Mahvira (900A.D)

$C_{r}^{n}=\frac{n !}{(n-r) ! r !}$

Herigeone (1634)

Aryabatai(499 A.D)

Pell(1685)

$N x^{2}+1=y^{2}$

and so on .

\section{References}

Balchandra. (1994). Indian mathematics. Janna Deep publication.

Berggren, J.L. (n.d.) Episodes in the mathematics of medieval Islam.

Lucas, N.H., Bunt-Philip, S., Jones, J. \& Bedient, D. (n.d.). The historical roots of elementary mathematics. Dover-x. 